\title{
Plasma osteopontin as a marker for future organ damage in pediatric systemic lupus erythematosus
}

\author{
Ornella J Rullo ${ }^{2}$, Jennifer MP Woo ${ }^{2}$, Alice DC Hoftman², Miriam F Parsa', Gil Amarilyo², Deborah K McCurdy², \\ Betty P Tsao ${ }^{3}$
}

From 2011 Pediatric Rheumatology Symposium sponsored by the American College of Rheumatology Miami, FL, USA. 2-5 June 2011

\section{Purpose}

Osteopontin (OPN) is a secreted phosphoprotein functioning in monocyte and $\mathrm{T}$ cell adhesion and migration. Expression of OPN in alternatively-activated macrophages has been implicated in post-inflammatory fibrosis of lung and kidney. In our previously conducted cross-sectional study of 72 pediatric SLE patients (pSLE; age of onset $<18$ years), increased circulating plasma OPN (cOPN) was observed in PSLE compared with healthy controls, and was associated of with ACR/SLICC damage index (SDI) scores $>1(p=0.0007$ and 0.001 , respectively), although there was no association with SLEDAI. We therefore propose that OPN is a marker for pSLE disease progression, and that increased cOPN levels may predict the development of organ damage.

\section{Methods}

17 pSLE patients have been followed for at least 6 months with cOPN measured by ELISA at baseline and at 6 month intervals. Serum Cr, urine protein/creatinine and GFR were recorded at baseline and every 6 months. SLEDAI was recorded at 3 month intervals, and at disease flare, and SDI at every 6 months. Cumulative disease activity (adjusted-mean SLEDAI, or AMS) was calculated by finding the area under the curve of serial SLEDAI measurements. Statistical analysis was performed using Student's t test, Pearson's correlation, and Fisher's exact test.

\section{Results}

6 of the 17 longitudinal subjects accumulated damage as per an increase in SDI during the course of the study (3 in the renal portion, 1 peripheral vascular, 1 pulmonary hypertension, 1 avascular necrosis). 5 of the 6 patients who accumulated damage had high cOPN levels (cOPN in the top quartile) in at least 1 of the previous 2 visits prior to the increase on SDI. $80 \%$ of subjects with a high cOPN had an increase in SDI, whereas only $11 \%$ of subjects with a cOPN in the bottom three quartiles had an increase in SDI, indicating an increase in SDI was more likely in those patients with a preceding high $\mathrm{cOPN}(\mathrm{p}=0.01)$. Cumulative disease activity (AMS) was associated with an increase in SDI scores $(\mathrm{p}<0.0001)$ in this cohort, and was correlated with cOPN levels (Spearman $\mathrm{r}=0.46, \mathrm{p}=0.02$ ).

\section{Conclusion}

cOPN is correlated with cumulative disease activity and may be a potential marker for future organ damage in pSLE. The rapid and/or early accrual of organ damage in patients with SLE has been associated with poorer outcomes, therefore a marker of risk for irreversible damage could be a critical component for guiding treatment decisions in PSLE.

\section{Disclosure}

Ornella J. Rullo: None; Jennifer M.P. Woo: None; Alice D.C. Hoftman: None; Miriam F. Parsa: None; Gil Amarilyo: None; Deborah K. McCurdy: None; Betty P. Tsao: None.

\section{Author details}

${ }^{1}$ UCLA, Manhattan Beach, CA, USA. ${ }^{2}$ UCLA, Los Angeles, CA, USA. ${ }^{3}$ UCLA School of Medicine, Los Angeles, CA, USA. 
Cite this article as: Rullo et al:: Plasma osteopontin as a marker for future organ damage in pediatric systemic lupus erythematosus. Pediatric Rheumatology 2012 10(Suppl 1):A123.

Submit your next manuscript to BioMed Central and take full advantage of:

- Convenient online submission

- Thorough peer review

- No space constraints or color figure charges

- Immediate publication on acceptance

- Inclusion in PubMed, CAS, Scopus and Google Scholar

- Research which is freely available for redistribution 